\title{
Selective nonoperative management of penetrating abdominal trauma at a level 1 Canadian trauma centre: a quest for perfection
}

\author{
Rogeh Habashi, MD \\ Angela Coates, MEd \\ Paul T. Engels, MD
}

Accepted Feb. 13, 2019

\section{Correspondence to: \\ P. Engels \\ Department of Surgery \\ McMaster University \\ Box 359 \\ 1280 Main St W \\ Hamilton ON L8S 4K1 \\ engelsp@mcmaster.ca}

DOI: $10.1503 /$ cjs.013018

\begin{abstract}
Background: Many patients who sustain penetrating abdominal trauma can be managed nonoperatively. The Eastern Association for the Surgery of Trauma (EAST) has published guidelines on selective nonoperative management (SNOM), and this approach is well established. The purpose of this study is to assess the management of penetrating abdominal trauma, including the selection of patients for SNOM and the use of this approach, at a Canadian level 1 trauma centre.
\end{abstract}

Methods: We used the Hamilton Health Sciences trauma registry to compile data on patients aged 16 years and older who sustained penetrating abdominal trauma from Jan. 1, 2011, to Dec. 31, 2017. Hemodynamically stable, nonperitonitic patients without evisceration or impalement were considered potentially eligible for SNOM. We compared the SNOM group of patients with the immediate operative (IOR) group. Our primary outcome was SNOM failure; secondary outcomes included length of stay, repeat imaging, computed tomography (CT) protocol, laparoscopy in left thoracoabdominal trauma, and nontherapeutic and negative laparotomies.

Results: We included 191 patients with penetrating abdominal trauma; 123 underwent SNOM and 68 underwent IOR. Of the 68 patients in the IOR group, 4 underwent nontherapeutic laparotomies. Of the 123 patients in the SNOM group, this approach failed in $7(5.7 \%)$. Patients who were successfully managed with SNOM had an average length of stay of 25.4 hours (7.9-43.0 h), with no repeat imaging in 34/35 (97.1\%). Only 5 of the 47 patients with flank/back wounds had a CT scan that included luminal contrast. Only 3 of the 58 patients with left thoracoabdominal wounds underwent sameadmission laparoscopy, all demonstrating diaphragmatic defects.

Conclusion: Our study demonstrates a high rate of compliance with the EAST SNOM guidelines, including minimal failure rate of SNOM and an efficient use of resources as demonstrated by reduced length of stay and minimal use of reimaging. We identified 2 opportunities for improvement: improved use of luminal contrast CT in patients with flank/back wounds and improved use of diagnostic laparoscopy in patients with left thoracoabdominal wounds.

Contexte : Il est possible de traiter non chirurgicalement bon nombre de traumatismes abdominaux pénétrant. L'Eastern Association for the Surgery of Trauma (EAST) a publié des lignes directrices sur une approche bien établie : le traitement non chirurgical sélectif (« selective nonoperative management », ou SNOM). Le but de cette étude est d'évaluer le traitement des traumatismes abdominaux pénétrants, y compris la sélection des patients en vue du SNOM et l'utilisation de cette approche dans un centre de traumatologie canadien de niveau 1.

Méthodes : Nous avons utilisé le registre de traumatologie du Hamilton Health Sciences Centre pour compiler les données sur les patients de 16 ans et plus ayant subi un traumatisme abdominal pénétrant entre le $1^{\text {er }}$ janvier 2011 et le 31 décembre 2017. Les patients hémodynamiquement stables, indemmes de péritonite, d'éviscération ou d'empalement ont été considérés pour le SNOM. Nous avons comparé les patients du groupe soumis au SNOM à ceux du groupe soumis à une intervention chirurgicale immédiate. Notre paramètre principal était l'échec du SNOM; les paramètres secondaires incluaient la durée du séjour, la reprise des épreuves d'imagerie, le protocole de tomodensitométrie (TDM), la laparoscopie dans les cas de traumatisme thoracoabdominal gauche et les laparotomies non thérapeutiques et négatives.

Résultats : Nous avons inclus 191 patients ayant subi un traumatisme abdominal pénétrant; 123 ont été soumis à l'approche SNOM et 68 à un une intervention chirurgicale immédiate. Parmi ces 68 patients, 4 ont subi des laparotomies non thérapeutiques. Parmi les 123 patients du groupe SNOM, l'approche a échoué chez 7 (5,7\%). Les patients traités avec succès par le SNOM ont séjourné en moyenne 25,4 heures 
(7,9-43,0 h), sans reprise d'imagerie chez 34/35 (97,1\%). Seulement 5 patients sur les 47 victimes de traumatisme au côté ou au dos ont subi une TDM avec contraste endoluminal. Seulement 3 patients sur 58 patients ayant une plaie thoraco-abdominale gauche ont subi des laparoscopies le jour même de l'admission et elles ont toutes révélé des anomalies diaphragmatiques.

Conclusion : Notre étude a démontré un taux élevé de conformité aux lignes directrices de l'EAST concernant le SNOM, y compris un taux minime d'échecs avec cette approche et une utilisation à bon escient des ressources, comme en témoignent l'abrègement des séjours et le recours minime à la reprise des épreuves d'imagerie. Nous avons relevé deux secteurs à améliorer, soit l'emploi plus judicieux de la TDM avec contraste endoluminal chez les victimes d'un traumatisme au dos ou au côté et de la laparoscopie chez les victimes d'un traumatisme thoraco-abdominal gauche.

enetrating abdominal trauma typically results from a gunshot or stabbing. The approach to treating patients with penetrating abdominal trauma depends on the mechanism, location and trajectory of injury, the hemodynamic and neurologic status of the patient, and other injuries. The goals of managing such patients are to identify injuries requiring surgical repair and avoid unnecessary laparotomy. It is established that patients with penetrating abdominal trauma require immediate operation if (a) they are hemodynamically unstable (i.e., nonresponders and transient responders to initial small-volume fluid bolus administration), (b) they are neurologically compromised (i.e., they are intubated, intoxicated or sustained an impairing neurologic injury), (c) they are peritonitic or (d) they show evidence of impalement or evisceration. ${ }^{1}$

Trauma laparotomies can be classified as therapeutic and unnecessary laparotomies. ${ }^{2}$ Therapeutic laparotomies are ones where a surgical intervention was indeed required. Unnecessary laparotomies can be further subdivided into nontherapeutic and negative laparotomies. Nontherapeutic laparotomy is any laparotomy where a stable injury was identified not requiring surgical repair (e.g., stable retroperitoneal hematoma, nonbleeding lacerations, nonbleeding/ expanding solid visceral hematomas). A negative laparotomy is any laparotomy where no other intraabdominal injuries are identified aside from peritoneal penetration.

Since the 1960s there has been a shift in practice from routine mandatory laparotomies for penetrating trauma to a selective approach based on various patient and injury factors. This has culminated in selective nonoperative management (SNOM). ${ }^{3,4}$ There are many benefits of successful SNOM, including reduced length of hospital stay and avoidance of unnecessary operations $(40 \%-70 \%$ reduction in operations for stab wounds and $5 \%-20 \%$ for gunshot wounds) ${ }^{5}$ without increased morbidity. ${ }^{4,6-8}$ This transition in practice has been potentiated by the introduction of refined diagnostic procedures and better resuscitation protocols. In 2010, the Eastern Association for the Surgery of Trauma (EAST) published guidelines on the nonoperative management of penetrating abdominal trauma. ${ }^{8}$

Aside from the absolute indications for trauma laparotomies, the management of penetrating abdominal trauma in the hemodynamically stable patient heavily relies on the location and trajectory of the injury, the physical examination and the use of screening computed tomography (CT). ${ }^{8}$ The 3 main regions are (a) the anterior abdomen, (2) the thoracoabdomen (defined as the circumferential band around the torso from the nipple-line superiorly to the lowest costal margin inferiorly) and (c) the flank/back. ${ }^{4}$ The management of anterior abdomen penetrating trauma relies heavily on serial clinical examinations, local wound exploration and focused assessment with sonography in trauma (FAST) and CT findings. ${ }^{4}$ For thoracoabdominal penetrating trauma, the management can be complex because (a) this is an overlap zone between the chest and abdomen and (b) diaphragmatic injuries are commonly missed (only $40 \%$ are identified on CT at the time of trauma). ${ }^{4,9}$ Thus, delayed routine diagnostic laparoscopy is indicated for left thoracoabdominal trauma. ${ }^{9-12}$ Finally, flank/back penetrating trauma is assessed mainly by imaging as the retroperitoneum is difficult to examine. From the radiologic perspective, there is evidence that oral and rectal contrast may enhance the ability to identify duodenal and colonic injuries, respectively, in such regions. ${ }^{13,14}$

A successful SNOM entails observation of the patient for 24 hours with serial clinical examinations and bloodwork leading up to discharge. ${ }^{8}$ The use of repeat imaging during this period of observation may also be considered but it is not part of the EAST guidelines. ${ }^{8}$ Failure of SNOM is defined as any change in clinical picture requiring a procedural intervention from the perspective of the abdominal trauma whether it is surgery or interventional radiology. ${ }^{8}$ On the basis of the existing literature, between $14 \%$ and $17 \%$ of cases may fail SNOM and require more invasive intervention for definitive management. ${ }^{15,16}$

The primary objective of the present study was to assess compliance with the EAST guidelines for SNOM at a Canadian level 1 trauma centre. Secondary objectives included assessing (a) length of stay, (b) rate of reimaging, (c) rates of oral/rectal CT contrast in flank injuries and (d) rates of diagnostic laparoscopy in left thoracoabdominal injuries in patients treated with the SNOM approach. To our knowledge, this is only the second study to evaluate the modern use of SNOM in the Canadian context. ${ }^{16}$ 


\section{Methods}

A retrospective chart review of the Hamilton Health Sciences Trauma Registry was conducted to identify all patients who sustained a penetrating abdominal trauma between Jan. 1, 2011, and Dec. 31, 2017, at the Hamilton General Hospital, a Canadian level 1 trauma centre. The registry captures all patients with an injury severity score (ISS) of 12 or greater or for whom a trauma team activation was initiated (activation criteria: severe penetrating injuries to head, neck, chest or abdomen). Our study inclusion criteria were (a) age 16 years or older, (b) admission through the emergency department and (c) evidence of thoracoabdominal, anterior abdominal, flank and/or back penetrating injury. All patients were managed according to the decisions of the treating surgeon; our study site does not have a local treatment algorithm for such patients.

\section{Statistical analysis}

We collected descriptive demographic data on the included patients. We compared patients on the basis of initial approach (operative v. SNOM) using $\chi^{2}$ or Student $t$ tests. The primary outcome of interest was the percentage who were allocated to SNOM and for whom this approach was successful (i.e., rate of failed SNOM requiring laparotomy). SNOM failure was defined as hemodynamic instability or peritonitis after admission requiring an intervention (i.e., surgery or interventional radiology) usually within 24 hours after presentation to the Hamilton General Hospital trauma bay. Secondary outcomes included hospital length of stay (LOS) and any reimaging of SNOM patients, frequency and protocol appropriateness of CT scanning according to injury location, rate of diagnostic laparoscopy in left thoracoabdominal injuries and rate of unnecessary laparotomies in the operative group. We performed the statistical analyses using SAS software version 9.3 (SAS Institute Inc.).

\section{Results \\ Demographics}

A total of 249 patients sustained a penetrating abdominal trauma between 2011 and 2017 (Fig. 1). Of these, 58 were excluded. The most common reason for exclusion was an injury outside the chest/abdomen causing the abdominal trauma $(n=$ 31), Thus, 191 patients were included in the study as having penetrating thoracoabdominal injury with evident pleural and/or peritoneal penetration; these patients were allocated to either the immediate operative (IOR) group or the SNOM group (Table 1). The IOR group had a higher incidence of gunshot wounds ( $25.0 \%$ v. $8.1 \%)$, a higher initial heart rate $(98$ v. 91 beats per minute), a higher rate of packed red blood cell transfusion (41.2\% v. $4.9 \%)$, a higher ISS (15.3 v. 9.9) and a longer hospital LOS (12.6 v. 4.1 d). In our study, 68/191 $(35.6 \%)$ of patients were allocated to the IOR group while the remainder allocated to the SNOM group were hemodynamically stable in the trauma bay with no signs of peritonitis, evisceration or impalement
Fig. 1. Flow chart of study cohort. ED = emergency department; IOR = immediate operative management; MAIS = Maximum Abbreviated Injury Scale; PAT = penetrating abdominal trauma; SNOM = selective nonoperative management. 


\begin{tabular}{|c|c|c|c|c|}
\hline \multirow[b]{2}{*}{ Characteristic } & \multicolumn{3}{|c|}{ No. $(\%)$ of cases* } & \multirow[b]{2}{*}{$p$ value } \\
\hline & $\begin{array}{l}\text { IOR group } \\
n=68\end{array}$ & $\begin{array}{l}\text { SNOM group } \\
n=123\end{array}$ & $\begin{array}{l}\text { Total } \\
n=191\end{array}$ & \\
\hline Age, $y r$, mean $\pm S D$ & $36.0 \pm 16$ & $33.6 \pm 14$ & $34.4 \pm 15$ & 0.29 \\
\hline Sex, male & $62(91.2)$ & $109(88.6)$ & $171(89.5)$ & 0.58 \\
\hline \multicolumn{5}{|l|}{ Transfer classification } \\
\hline Direct from scene to lead trauma centre & 48 (70.6) & $85(69.1)$ & $133(69.6)$ & 0.83 \\
\hline Transfer from another hospital & $20(29.4)$ & $38(30.9)$ & $58(30.4)$ & \\
\hline \multicolumn{5}{|l|}{ Mechanism of injury } \\
\hline Stab wound & $49(72.1)$ & $111(90.2)$ & $160(83.8)$ & $<0.01$ \\
\hline Gunshot wound & $17(25.0)$ & $10(8.1)$ & $27(14.1)$ & \\
\hline Other penetrating wound & $2(2.9)$ & $2(1.6)$ & $4(2.1)$ & \\
\hline \multicolumn{5}{|l|}{ Location of wound(s) } \\
\hline Anterior abdomen & $43(63.2)$ & $28(22.8)$ & $71(37.2)$ & $<0.001$ \\
\hline Thoracoabdomen & $29(42.6)$ & $81(65.9)$ & $110(57.6)$ & $<0.01$ \\
\hline Flank & $12(17.6)$ & $16(13.0)$ & $28(14.7)$ & 0.39 \\
\hline Back & $4(5.9)$ & $15(12.2)$ & $19(9.9)$ & 0.16 \\
\hline \multicolumn{5}{|l|}{ Cause } \\
\hline Assault & $50(73.5)$ & $101(82.1)$ & $151(79.1)$ & 0.33 \\
\hline Self-inflicted & $15(22.1)$ & $17(13.8)$ & $32(16.8)$ & \\
\hline Accidental/other & $3(4.4)$ & $5(4.1)$ & $8(4.2)$ & \\
\hline \multicolumn{5}{|l|}{ Vitals at arrival at lead trauma centre } \\
\hline Heart rate, mean \pm SD & $98 \pm 25$ & $91 \pm 19$ & $94 \pm 21$ & $<0.05$ \\
\hline Systolic blood pressure, mean \pm SD & $126 \pm 25$ & $130 \pm 21$ & $129 \pm 22$ & 0.19 \\
\hline Respiration rate, mean $\pm \mathrm{SD}$ & $20 \pm 6$ & $20 \pm 6$ & $20 \pm 6$ & 0.76 \\
\hline \multicolumn{5}{|l|}{ ED procedures } \\
\hline CT scan & $33(48.5)$ & $104(84.6)$ & $137(71.7)$ & $<0.001$ \\
\hline Angiography & $9(13.2)$ & $20(16.3)$ & $29(15.2)$ & 0.68 \\
\hline Chest tube & $12(17.6)$ & $32(26.0)$ & $44(23.0)$ & 0.19 \\
\hline FAST & $28(41.2)$ & $59(48.0)$ & $87(45.5)$ & 0.37 \\
\hline Transfusion of PRBCs & $28(41.2)$ & $6(4.9)$ & $34(17.8)$ & $<0.001$ \\
\hline \multicolumn{5}{|l|}{ Post-ED destination } \\
\hline Operating room & $63(92.6)$ & $9(7.3)$ & $72(37.7)$ & $<0.001$ \\
\hline Intensive care unit or step-down bed & $3(4.4)$ & $45(36.6)$ & $48(25.1)$ & \\
\hline Ward & $2(2.9)$ & $59(48.0)$ & $61(31.9)$ & \\
\hline Transferred to another acute hospital & $0(0.0)$ & $1(0.8)$ & $1(0.5)$ & \\
\hline ED inpatient admission & $0(0.0)$ & $5(4.1)$ & $5(2.6)$ & \\
\hline Home & $0(0.0)$ & $4(3.3)$ & $4(2.1)$ & \\
\hline Injury Severity Score, mean \pm SD & $15.3 \pm 9$ & $9.9 \pm 6$ & $11.8 \pm 7$ & $<0.001$ \\
\hline \multicolumn{5}{|l|}{ Hospital length of stay, $d$} \\
\hline Mean \pm SD & $12.6 \pm 24$ & $4.1 \pm 5$ & $7.2 \pm 15$ & $<0.001$ \\
\hline Median (min, max) & $6(1,181)$ & $3(1,43)$ & $4(1,181)$ & \\
\hline 75th percentile & 12 & 5 & 7 & \\
\hline 90th percentile & 24 & 8 & 13 & \\
\hline $\begin{array}{l}\text { In-hospital death (excludes death en route, left } \\
\text { AMA) }\end{array}$ & $3(4.4)$ & $1(0.8)$ & $4(2.1)$ & 0.13 \\
\hline \multicolumn{5}{|c|}{$\begin{array}{l}\text { AMA = against medical advice; } C \mathrm{CT}=\text { computed tomography; } E D=\text { emergency department; } F A S T=\text { focused assessment with sonography in } \\
\text { trauma; IOR = immediate operative management; } \mathrm{PRBC}=\text { packed red blood cells; } \mathrm{SD}=\text { standard deviation; } \mathrm{SNOM}=\text { selective nonoperative } \\
\text { management. } \\
\text { *Unless indicated otherwise. }\end{array}$} \\
\hline
\end{tabular}

(Fig. 2). The most common location of injury was the anterior abdomen in the IOR group $(43 / 68,63.2 \%)$ and the thoracoabdomen in the SNOM group (81/123, $65.9 \%$; Table 1). Of note, back injuries were observed more frequently in the SNOM group than in the IOR group (12. $2 \%$ v. $5.9 \%)$.

\section{Primary outcome}

SNOM failed in $7 / 123$ patients (5.7\%). Three patients required a laparotomy both (a) for delayed peritonitis on assessment by staff surgeon on call and (b) because a formal staff radiologist report queried a hollow viscous injury 


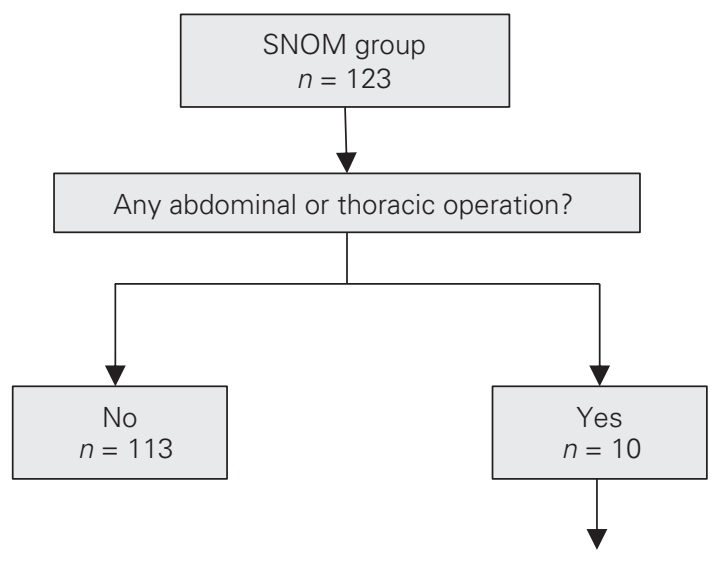

Fig. 2. Clinical course of the selective nonoperative management (SNOM) group. See Table 2 for supplementary data on the patients who underwent eventual operative management.

Table 2. Supplementary information for the SNOM patients from Figure 2 who underwent eventual operative management

\begin{tabular}{|c|c|c|}
\hline Indication for operation & Operative findings & $\begin{array}{l}\text { Failure of } \\
\text { SNOM?* }\end{array}$ \\
\hline $\begin{array}{l}\mathrm{L} \text { anterior } \\
\text { thoracoabdominal GSW }\end{array}$ & $\begin{array}{l}\text { Small L diaphragmatic defect (12-h } \\
\text { delay) }\end{array}$ & No \\
\hline $\begin{array}{l}\mathrm{L} \text { anterior } \\
\text { thoracoabdominal SW }\end{array}$ & $\begin{array}{l}\text { L diaphragmatic defect and HTX } \\
\text { (24-h delay) }\end{array}$ & No \\
\hline $\begin{array}{l}\text { L posterior } \\
\text { thoracoabdominal SW }\end{array}$ & $\mathrm{L}$ diaphragmatic defect (48-h delay) & No \\
\hline $\begin{array}{l}\text { Dropping Hgb } \\
\text { (hemodynamically } \\
\text { unstable) RLQ SW }\end{array}$ & $\begin{array}{l}\text { IR embolization of R deep } \\
\text { circumflex artery } \\
\text { pseudoaneurysm (10-h delay) }\end{array}$ & Yes \\
\hline $\begin{array}{l}\text { Dropping Hgb } \\
\text { (hemodynamically } \\
\text { unstable) RUQ SW }\end{array}$ & $\begin{array}{l}\text { IR embolization of } L \text { hepatic artery } \\
\text { pseudoaneurysm (72-h delay) }\end{array}$ & Yes \\
\hline $\begin{array}{l}\text { Local peritonitis in } 10 \mathrm{~h} \\
\text { formal CT queried a } \\
\text { terminal ileum injury } \\
\text { (supraumbilical SW) }\end{array}$ & $\begin{array}{l}\text { AW hematoma, traumatic hernia } \\
\text { repair (nontherapeutic laparotomy) }\end{array}$ & Yes \\
\hline $\begin{array}{l}\text { Local peritonitis in } 12 \mathrm{~h} \\
(\mathrm{~L} \text { flank SW) }\end{array}$ & $\begin{array}{c}\text { Devascularized descending colon } \\
\text { requiring resection, splenic } \\
\text { laceration grade II (therapeutic } \\
\text { laparotomy) }\end{array}$ & Yes \\
\hline $\begin{array}{l}\text { Local peritonitis in } 14 \mathrm{~h} \\
\text { (LUQ SW) }\end{array}$ & $\begin{array}{l}\text { Small bowel laceration with } \\
\text { devascularization requiring } \\
\text { resection (therapeutic laparotomy) }\end{array}$ & Yes \\
\hline $\begin{array}{l}\text { Hemodynamilcally } \\
\text { unstable in } 2 \mathrm{~h} \\
(\mathrm{~L} \text { anterior } \\
\text { thoracoabdominal GSW) }\end{array}$ & $\begin{array}{c}\text { Massive } \mathrm{HTX}>1.5 \mathrm{~L} \text { with } \mathrm{RML} \\
\text { laceration requiring repair } \\
\text { (therapeutic right anterior } \\
\text { thoracotomy) }\end{array}$ & Yes \\
\hline $\begin{array}{l}\text { Hemodynamically } \\
\text { unstable in } 4 \mathrm{~h} \\
\text { (R anterior } \\
\text { thoracoabdominal SW) }\end{array}$ & $\begin{array}{l}\text { Massive HTX }>1.5 \mathrm{~L} \text { with right } \\
\text { pulmonary artery and internal } \\
\text { mammary artery laceration } \\
\text { requiring repair (therapeutic right } \\
\text { posterior thoracotomy) }\end{array}$ & Yes \\
\hline \multicolumn{3}{|c|}{$\begin{array}{l}\mathrm{AW}=\text { abdominal wall; } \mathrm{CT}=\text { computed tomography; } \mathrm{GSW}=\text { gunshot wound; } \mathrm{Hgb}= \\
\text { hemoglobin; } \mathrm{HTX}=\text { hemothorax; } \mathrm{IR}=\text { interventional radiology; } \mathrm{LUQ}=\text { left upper quadrant } \\
\mathrm{RLQ}=\text { right lower quadrant; } \mathrm{RML}=\text { right middle lobe; } \mathrm{SNOM} \text { selective nonoperative } \\
\text { management; } \mathrm{SW}=\text { stab wound. } \\
{ }^{*} \text { Defined as change in clinical picture requiring a procedural intervention. }\end{array}$} \\
\hline
\end{tabular}

the next morning. Two needed emergent thoracotomies because of (a) massive hemothoraces (> 1.5 L/2 h) and (b) hemodynamic instability despite resuscitation. We have designated these cases as SNOM failures because both patients had thoracoabdominal wounds placing them at risk for intraabdominal injuries and were initially managed in an expectant fashion (i.e., SNOM) rather than being taken for immediate abdominal or thoracic exploration. Finally, 2 patients underwent interventional radiology embolization of traumatic lacerations because of (a) hemodynamic instability and (b) active extravasation on rescanning (Table 2). Six of the 7 interventions were therapeutic. Out of the 58 patients with left thoracoabdominal injuries in the SNOM group, only 3 underwent delayed diagnostic laparoscopy to rule out diaphragmatic injuries and all 3 of these patients demonstrated an injury.

\section{Secondary outcomes}

\section{Length of stay and reimaging in the SNOM group}

To assess for appropriate length of stay and use of reimaging in the SNOM group, we excluded 88 patients who had confounders of prolonged stay including (a) psychiatric forms, (b) any procedures (including chest tube placement) related or not to injury at any point during index admission and (c) other complications (injury related, infection related or iatrogenic). Excluding confounders, we were left with 35 SNOM patients who had an average LOS of 25.4 hours $(7.9-43.0$ h). Only $1 / 35$ (2.9\%) had a prolonged unexplained 3-day stay for a grade II splenic laceration; this patient was clinically stable with unwavering hemoglobin level. In regard to reimaging, the EAST guidelines were followed for $34 / 35$ patients with observation only for 24 hours after the initial assessment without reimaging. The single patient who underwent repeat imaging needed it because the patient had refused intravenous (IV) contrast for the initial CT scan and had worsening abdominal pain within 24 hours after admission, necessitating a new CT with IV contrast.

\section{Frequency and appropriateness of CT based on injury location in the SNOM group}

In the SNOM group, 119/123 patients (96.7\%) underwent screening CT of the site of injury as per the EAST guidelines. Only 4 patients did not have any CT screening, all of whom had sustained left anterior thoracoabdominal stab wounds. One of these was a pregnant female (17 wk gestational age) presenting with tension pneumothorax requiring a thoracostomy drain. The patient was assessed by the staff radiologist in the trauma bay, who performed a focused ultrasound scan to minimize radiation as the patient remained clinically stable. Two other patients had a pneumothorax requiring thoracostomy decompression but we could not determine the reason a CT scan was not performed by chart review. One patient 


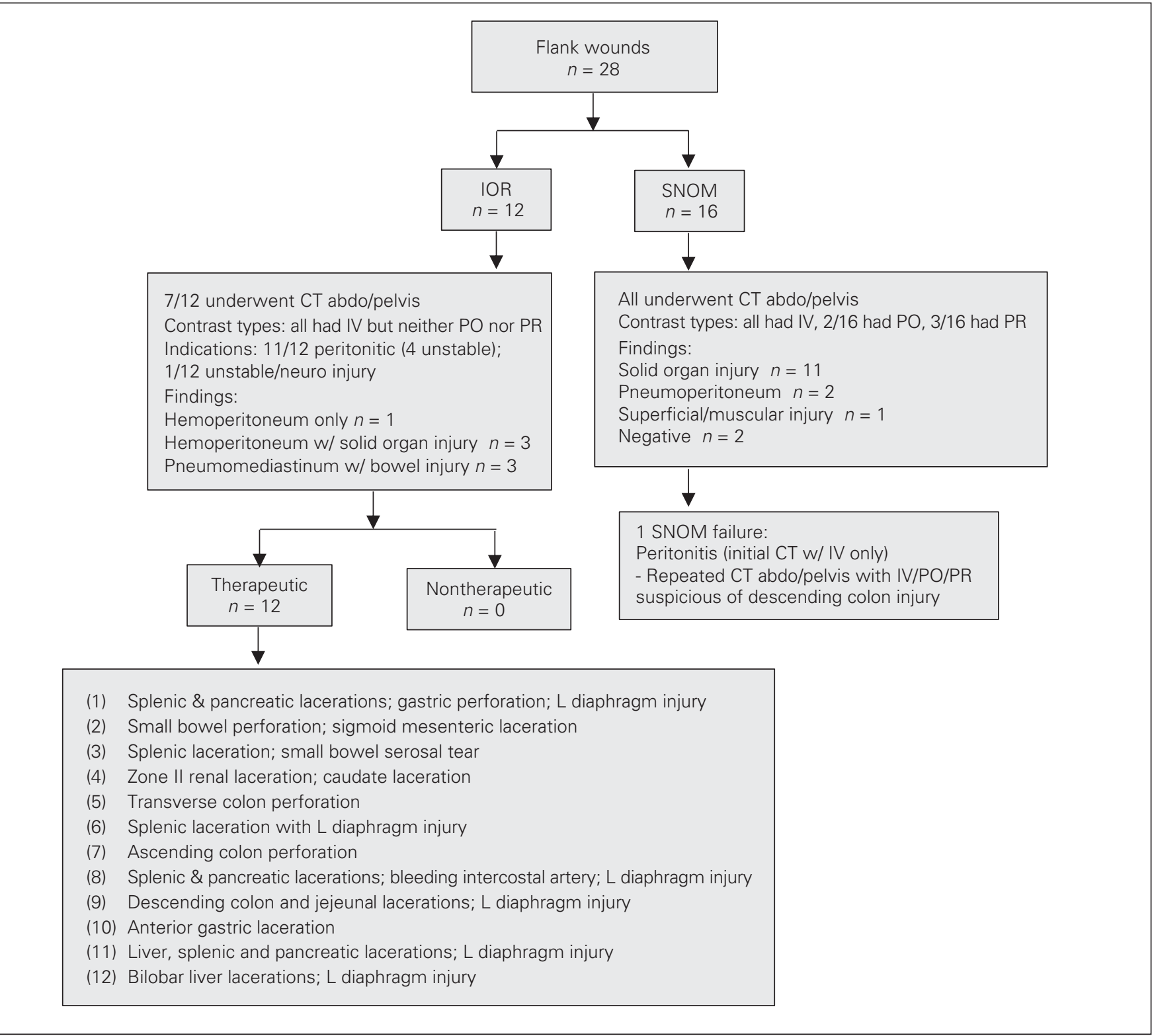

Fig. 3. Clinical course of patients with flank wounds. CT = computed tomography; $\mathrm{GI}=$ gastrointestinal, IOR = immediate operative management; $\mathrm{L}=$ left; $\mathrm{PO}=$ per os; $\mathrm{PR}=$ per rectum; $\mathrm{SNOM}$ = selective nonoperative management.

had a normal chest radiograph with no respiratory distress and hence the trauma team leader elected not to expose the patient to further CT radiation.

Only 5 of the 47 patients with flank/back wounds had a CT scan that included luminal contrast. Of the 28 patients who sustained flank injuries (16 in the SNOM group, 12 in the IOR group), only 3 underwent initial CT abdomen and pelvis scanning with rectal contrast, and 2 had PO contrast to rule out retroperitoneal colonic injury (Fig. 3). None had triphasic contrast CT (intravenous [IV], per os $[\mathrm{PO}]$ and per rectum $[\mathrm{PR}])$. All 12 patients in the IOR group underwent therapeutic operations. One of the 16 patients with flank wounds in the SNOM group experienced SNOM failure, and repeat CT abdomen and pelvis scanning with PR confirmed that this person had a descending colon injury mandating a laparotomy and subsequent segmental descending colon resection.

Rate of diagnostic laparoscopy for left thoracoabdominal penetrating trauma in the SNOM group

Of the 58 patients with left thoracoabdominal injuries in the SNOM group, only 3 underwent planned diagnostic laparoscopy (Fig. 4 and Table 3) and injuries were found in all 3 of these patients. Of the 3 planned diagnostic laparoscopies, both chest radiography and CT chest scanning completely missed any diaphragmatic defects. In 1 case, the radiologist suspected a diaphragmatic defect only because of the tract of injury (gunshot wound from the left thorax to the left abdomen), rather than because of any radiologic findings. Two of the planned diagnostic 


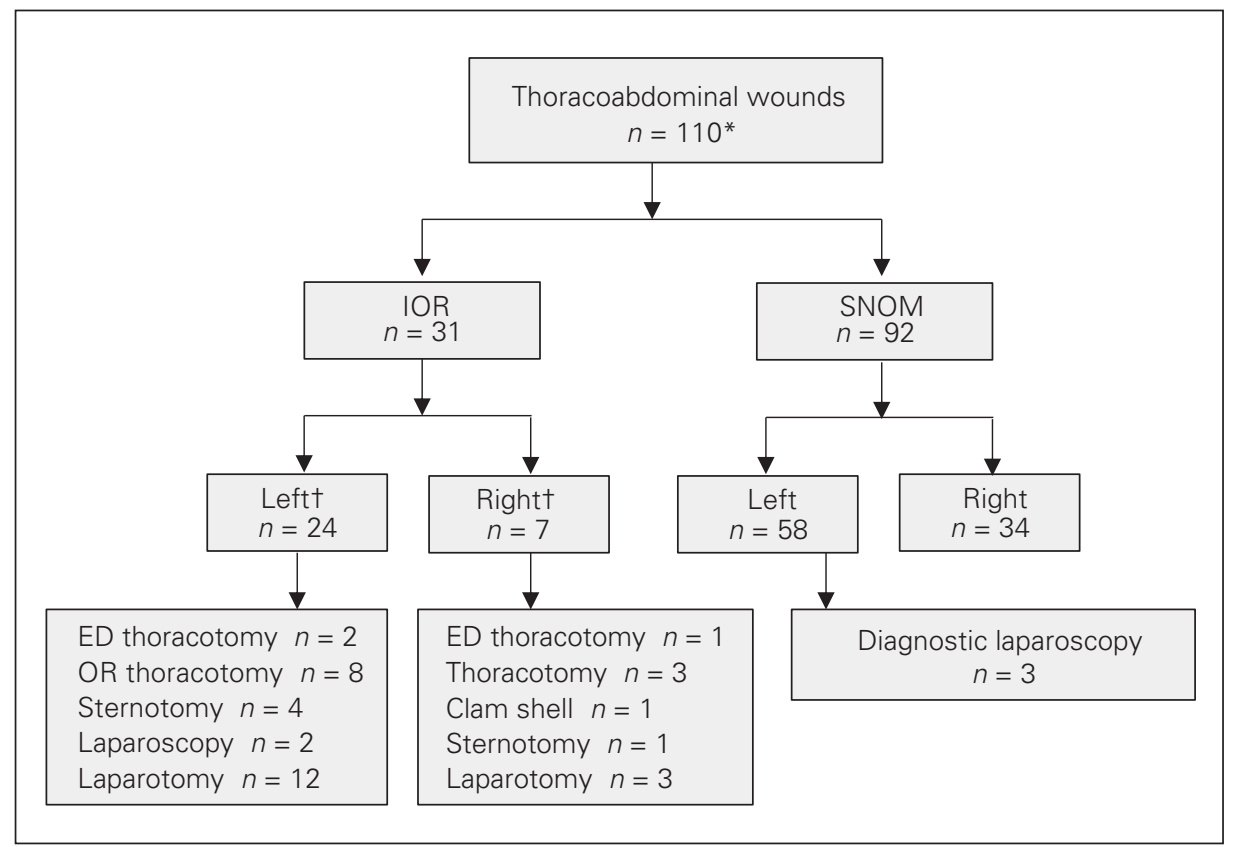

Fig. 4. Clinical course of the patients with thoracoabdominal wounds. *The sum of immediate operative management (IOR) + selective nonoperative management (SNOM) cases exceeds 110 because 13 cases had simultaneous bilateral thoracoabdominal injuries. †The sum exceeds the total because some patients had simultaneous/combined surgeries. See Table 3 for supplementary data on the patients who underwent diagnostic laparoscopy. $\mathrm{ED}=$ emergency department; $\mathrm{OR}=$ operating room.

Table 3. Supplementary information for the SNOM patients from Figure 4 who underwent diagnostic laparoscopy

\begin{tabular}{|c|c|c|c|}
\hline $\begin{array}{l}\text { Indication for } \\
\text { operation }\end{array}$ & Operative findings & CXR & CT chest \\
\hline $\begin{array}{l}\mathrm{L} \text { anterior } \\
\text { thoracoabdominal } \\
\text { GSW }\end{array}$ & $\begin{array}{c}\text { Small L } \\
\text { diaphragmatic } \\
\text { defect } \\
\text { (12-h delay) }\end{array}$ & Normal & $\begin{array}{l}\text { ?tract from } L \\
\text { thorax to } L \\
\text { abdomen } \\
\text { suspicious for } \\
\text { diaphragmatic } \\
\text { defect }\end{array}$ \\
\hline $\begin{array}{l}\mathrm{L} \text { anterior } \\
\text { thoracoabdominal } \\
\text { SW }\end{array}$ & $\begin{array}{c}\text { L diaphragmatic } \\
\text { defect and HTX } \\
\text { (24-h delay) }\end{array}$ & $\begin{array}{l}\text { Small } \\
\text { left } \\
\text { pleural } \\
\text { effusion }\end{array}$ & $\begin{array}{c}\text { Left HTX with mild } \\
\text { hemidiaphragmatic } \\
\text { elevation but no } \\
\text { diaphragmatic } \\
\text { defect }\end{array}$ \\
\hline $\begin{array}{l}\text { L posterior } \\
\text { thoracoabdominal } \\
\text { SW }\end{array}$ & $\begin{array}{c}\text { L diaphragmatic } \\
\text { defect } \\
\text { (48h delay) }\end{array}$ & Normal & $\begin{array}{c}\text { Trace PTX. No } \\
\text { diaphragmatic } \\
\text { defect }\end{array}$ \\
\hline
\end{tabular}

GSW = gunshot wound; HTX = hemothorax; $L$ = left; PTX = pneuomothorax; SNOM = selective nonoperative management; $\mathrm{SW}=\mathrm{stab}$ wound.

laparoscopies for diaphragmatic defects were performed within 24 hours and 1 at 48 hours. As this is a retrospective study, we were unable to determine the reason why the latter patient waited until the 48-hour mark.

Upon further review of the 58 patients who sustained left thoracoabdominal penetrating trauma, we identified 6 patients for whom radiologic imaging queried diaphragmatic defects. In $2 / 6$ cases, chest radiographs revealed a mildly elevated left hemidiaphragm. In 2/6 CT chest scans, there were visible diaphragmatic defects $(1.2$ and $2 \mathrm{~cm}$, respectively). In 1/6 CT chest scans, there was evidence of bilateral hemothoraces that raised suspicion for diaphragmatic defects. Finally, in 1/6 CT chest scans, the radiologist queried a diaphragmatic injury on the basis of the tract traversing from the anterior chest to the left abdomen. These 6 cases did not undergo the same-admission diagnostic laparoscopy or videoassisted thoracoscopic surgery (VATS); although it is possible that some of these patients may have subsequently undergone hospital readmission and/or delayed evaluation at another hospital within our region, none did so at our trauma centre.

For the 12 patients in the IOR group with intraoperatively confirmed diaphragmatic defects, $12 / 12$ chest radiographs failed to show any signs of diaphragmatic traumatic disruption. Only $1 / 5$ CT chest scans suggested a possible left diaphragmatic injury on the basis of proximity to the inferior edge of the left lateral hemidiaphragm with associated atelectasis of left lung base.

\section{Rate of unnecessary laparotomy/laparoscopy in the IOR group}

Among patients in the IOR group, the main reasons to operate were (a) peritonitis (48.5\% of patients, 33/68), (b) hemodynamic instability in the opinion of the treating surgeon $(44.1 \%, 30 / 68)$ and (c) evisceration (16.2\%, 11/68). Only 2 patients underwent interventional radiology (IR) embolizations (1 for a bleeding retroperitoneal pseudoaneurysm and 1 for a bleeding hepatic segment $4 \mathrm{~b}$ laceration); both of these patients were not acutely transferred but rather stabilized first in the intensive care unit with further imaging before the IR intervention. There were 3 nontherapeutic laparotomies and 1 negative laparotomy (Fig. 5 and Table 4). Three operations were deemed nontherapeutic with the following findings: (a) a stable mesenteric hematoma (laparoscopy), (b) a nonbleeding omental laceration (laparotomy) and (c) nonexpanding 2-cm anterior superior hepatic contusion (laparotomy), respectively. One operation did not demonstrate any intraabdominal injuries but a laparotomy was indicated because of impalement with knife in situ.

\section{Discussion}

The paradigm shift away from routine trauma laparotomy for penetrating abdominal trauma to SNOM has reduced the 
number of unnecessary operations and associated postoperative complications and reduced LOS, with no increase in morbidity. ${ }^{4,8}$ Our study describes a cohort of 191 patients with penetrating abdominal trauma of whom 123 (64.4\%) were assigned to SNOM. Although reported rates of SNOM usage are variable and range from $49 \%$ to $90 \%,{ }^{2,13,16}$ given our low rate of nontherapeutic laparotomy in the IOR group $(6 \%, 4 / 68)$, we believe that patient selection for SNOM at our institution is indeed highly appropriate. The decreased allocation for SNOM in our study may also be due to inclusion of thoracoabdominal traumas, for which higher operative rates have been reported. We emphasize the high rate of success for our SNOM group, with only 7/123 failing (5.7\%) compared with the literature failure rate of $14.5 \%-21 \% .{ }^{2,14-16}$

Our SNOM management was also found to be efficient. The LOS for those patients without other reasons to keep them in hospital was just over 1 day, consistent with the period of 24 hours of clinical observation recommended in the EAST guidelines. In comparison, the reported LOS averages $2-3$ days in the literature. ${ }^{14-16}$ It must be noted that we removed patients with confounders for extended LOS from our analysis. Furthermore, the low rate of repeat imaging, which at times may be necessary in the context of the clinical situation, during this period of in-patient observation (1 out of 35$)$ represents an efficient use of resources.

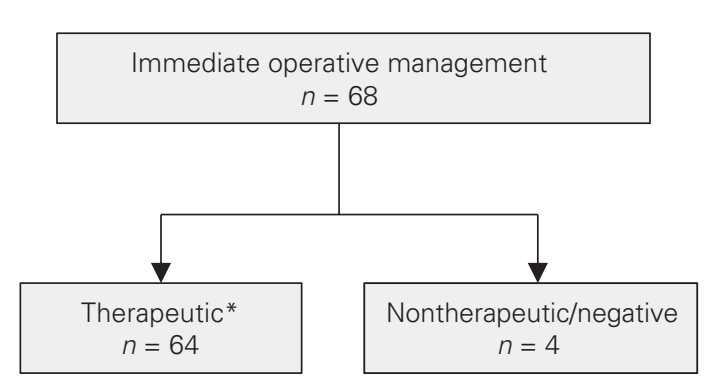

Fig. 5. Therapeutic and unnecessary (nontherapeutic or negative) laparotomies and laparoscopies in the immediate operative management group. See Table 4 for supplementary data on the patients who had an unnecessary laparotomy or laparoscopy. *The total in this box is 64 because the 32 patients who underwent a thoracotomy in the emergency department were duplicated in the thoracotomy group.
In the cohort undergoing SNOM, a screening CT scan was performed in $96.7 \%$ (119/123) of cases, demonstrating a high rate of compliance with the EAST guidelines. However, despite evidence showing the utility of oral/rectal contrast in ruling out retroperitoneal colonic injuries, ${ }^{13}$ only 5 of 16 patients with flank injuries in the SNOM group underwent double-contrast CT (3 PR and $2 \mathrm{PO})$. To highlight the significance of this, the single SNOM failure among patients with a flank injury underwent a repeat CT with PR contrast that confirmed a descending colon injury mandating a laparotomy and segmental colonic resection. This clearly represents an opportunity for quality improvement at our centre.

Another prominent finding was the poor correlation between CT findings of diaphragmatic injuries and operative evidence of diaphragmatic defects. In the 3 cases of delayed diagnostic laparoscopy of left thoracoabdominal traumas, none of the chest radiographs or CT chest scans convincingly identified the diaphragmatic defects; however, in 1 case, a diaphragmatic defect was suspected solely on the basis of the trajectory of the gunshot traversing the left thorax to the left abdomen (Fig. 4). Similarly, for the 12 patients in the IOR group with confirmed diaphragmatic defects, none of the chest radiographs showed any diaphragmatic injury. Only 1 of the 5 CT chest scans was suspicious of a left diaphragmatic injury on the basis of proximity to the inferior edge of left lateral hemidiaphragm. These findings are consistent with the radiologic literature of the CT miss rate of diaphragmatic defects, ranging between $12 \%$ and $63 \%$, with associated delayed presentations of strangulation or significant intrathoracic visceral herniation resulting in mortality rates reaching $30 \%-60 \%{ }^{11,17}$ Our study further emphasizes the superiority of diagnostic laparoscopy over screening CT in ruling out diaphragmatic defects in the context of penetrating left thoracoabdominal traumas. ${ }^{8,11,12}$

Our retrospective review revealed that only $3 / 58$ patients with left thoracoabdominal trauma were offered delayed diagnostic laparoscopy. Extrapolation based on literature values suggests that up to $50 \%$ of all patients with left thoracoabdominal penetrating trauma may sustain a diaphragmatic defect. ${ }^{10}$ This indicates that 26 cases of diaphragmatic defects may have been missed in our cohort.

Table 4. Supplementary data for the patients from Figure 5 who had a nontherapeutic or negative laparotomy or laparoscopy

\begin{tabular}{|c|c|c|c|}
\hline Indication for operation & Operation & Operative findings & Type \\
\hline $\begin{array}{l}\text { Diffuse peritonitis (LUQ SW) CT: } \\
\text { tiny blush per mesentery }\end{array}$ & Diagnostic laparoscopy & $\begin{array}{l}\text { Stable mesenteric hematoma; trace hemoperito- } \\
\text { neum }\end{array}$ & Nontherapeutic \\
\hline $\begin{array}{l}\text { ?FAST+ RUQ } \\
\text { (umbilical SW) }\end{array}$ & Laparotomy & Nonbleeding omental laceration & Nontherapeutic \\
\hline $\begin{array}{l}\text { ?GSW anterior abdomen (LUQ/RUQ } \\
\text { GSW) }\end{array}$ & Laparotomy & $\begin{array}{l}\text { Tangential GSW; } 2 \mathrm{~cm} \text { anterior superior hepatic } \\
\text { contusion (segment 4) }\end{array}$ & Nontherapeutic \\
\hline $\begin{array}{l}\text { Knife in situ } \\
\text { (supraumbilical SW) }\end{array}$ & Laparotomy & Negative aside from peritoneal penetration & Negative \\
\hline
\end{tabular}


Such findings highlight a need to track our left thoracoabdominal penetrating traumas and set up routine delayed diagnostic laparoscopy within 24 hours of presentation to rule out acute traumatic diaphragmatic defects and thereby avoid highly morbid and mortal delayed presentations of intrathoracic strangulation of abdominal viscera.

On the basis of our study results, we recommend that any patient presenting with penetrating abdominal trauma (stab wound or low-velocity gunshot wound) in the absence of peritonitis, hemodynamic instability or evisceration be considered for SNOM. Patients with a penetrating injury trajectory involving the flanks should undergo initial screening CT scanning with rectal contrast, and patients with a penetrating injury trajectory involving the left thoracoabdomen should undergo planned sameadmission diagnostic laparoscopy to rule out diaphragmatic injury. This recommendation is consistent with the Western Trauma Association's algorithm for abdominal stab wounds, ${ }^{18}$ which was published after the submission of this manuscript to the Canadian fournal of Surgery.

\section{Limitations}

Our study is retrospective in nature and is based on trauma registry and chart review, with all of the inherent limitations that exist with such methodology and data sources. Nevertheless, we diligently examined each medical record to best determine the patient's clinical presentation and the decision-making process of the health care providers at the time. As we did not have access to the patient's records outside of our trauma centre, any postdischarge presentations to other hospitals were not captured. Our LOS analysis excluded 88 of the 123 SNOM patients with confounders; the clinical relevance of our LOS result must be interpreted within this context. Although our cohort size was only 191 patients from a single centre, to our knowledge this represents the largest reported study examining the use of SNOM in the Canadian context to date.

\section{Conclusion}

Our study demonstrates components of effective management of penetrating abdominal trauma at our level 1 Canadian trauma centre, including the appropriate selection of patients for SNOM, the low failure rate of patients treated with the SNOM approach and the efficient use of hospital resources for these patients. Opportunities for improvement include increasing the use of CT scanning with luminal contrast in back/flank wounds and the mandatory use of diagnostic laparoscopy in patients with left thoracoabdominal wounds to rule out diaphragmatic injury.

Affiliations: From the Department of Surgery, McMaster University, Hamilton, Ont.
Competing interests: None declared.

Contributors: All authors designed the study. R. Habashi acquired the data, which all authors analyzed. All authors wrote and reviewed the article, approved the final version for publication and agreed to be accountable for all aspects of the work.

\section{References}

1. Krin C, Brohi K. Penetrating abdominal trauma: guidelines for evaluation. London (UK): TRAUMA.ORG; 9 Aug. 2004. Available: www. trauma.org/archive/abdo/penetrating.html (accessed 8 Dec. 2015).

2. Ertekin C, Yanar H, Taviloglu K, et al. Unnecessary laparotomy by using physical examination and different diagnostic modalities for penetrating abdominal stab wounds. Emerg Med f 2005;22:790-4.

3. Oyo-Ita A, Ugare UG, Ikpeme IA. Surgical versus non-surgical management of abdominal injury. Cochrane Database Syst Rev 2015;13:CD007383.

4. Ball C. Current management of penetrating torso trauma: nontherapeutic is not good enough anymore. Can 7 Surg 2014;57:E36-43.

5. Leppäniemi AK, Salo J, Haapiainen RK. Complications of negative laparotomy for truncal stab wounds. 7 Trauma 1995;38:54-8.

6. Renz BM, Feliciano DV. Unnecessary laparotomies for trauma: a prospective study of morbidity. 7 Trauma 1995;38:350-6.

7. Morrison JE, Wisner DH, Bodai BI. Complications after negative laparotomy for trauma: long-term follow-up in a health maintenance organization. F Trauma 1996;41:509-13.

8. Como J, Bokhari F, Chiu WC, et al. EAST practice management guidelines for selective nonoperative management of penetrating abdominal trauma. 7 Trauma 2010;68:721-33.

9. Uribe RA, Pachon CE, Frame SB, et al. A prospective evaluation of thoracoscopy for the diagnosis of penetrating thoracoabdominal trauma. 7 Trauma 1994;37:650-4.

10. Kumar S, Pol M, Mishra B, et al. Traumatic diaphragmatic injury: a marker of serious injury challenging trauma surgeons. Indian 7 Surg 2015;77(Suppl 2):666-9.

11. Koto Z, Mosai F, Matsevych O. The use of laparoscopy in managing penetrating thoracoabdominal injuries in Africa: 83 cases reviewed. World 7 Emerg Surg 2017;12:27.

12. McDonald A, Robinson B, Alarcon L, et al. Evaluation and management of traumatic diaphragmatic injuries: a practice management guideline from the Eastern Association for the Surgery of Trauma. 7 Trauma Acute Care Surg 2018;85:198-207.

13. Himmelman RG, Martin M, Gilkey S, et al. Triple-contrast CT scans in penetrating back and flank trauma. F Trauma 1991;31:852-5.

14. Shanmuganathan K, Mirvis SE, Chiu WC, et al. Penetrating torso trauma: triple-contrast helical CT in peritoneal violation and organ injury - a prospective study in 200 patients. Radiology 2004;231:775-84.

15. Leppäniemi AK, Haapiainen RK. Selective nonoperative management of abdominal stab wounds: prospective, randomized study. World F Surg 1996;20:1101-5.

16. Bennett S, Amath A, Knight H, et al. Conservative versus operative management in stable patients with penetrating abdominal trauma: the experience of a Canadian level 1 trauma centre. Can 7 Surg 2016;59:317-21.

17. Panda A, Kumar A, Gamanagatti S, et al. Traumatic diaphragmatic injury: a review of CT signs and the difference between blunt and penetrating injury. Diagn Interv Radiol 2014;20:121-8.

18. Martin MJ, Brown CVR, Shatz DV, et al. Evaluation and management of abdominal stab wound: a Western Trauma Association critical decisions algorithm. F Trauma Acute Care Surg 2018;85:1007-15. 